\title{
Genetic transformation of lignin degrading fungi facilitated by Agrobacterium tumefaciens
}

\author{
Krishna K Sharma, Ramesh C Kuhad ${ }^{*}$
}

\begin{abstract}
Background: White-rot fungi are primarily the major degraders of lignin, a major obstacle for commercial exploitation of plant byproducts to produce bioethanol and other industrially important products. However, to improve their efficacy for lignin degradation, it has become necessary to genetically modify these organisms using appropriate vectors. Agrobacterium tumefaciens, a soil phytopathogenic bacterium, generally transforms plants by delivering a portion of the resident Ti- plasmid, the T-DNA (transfer DNA). The trans-Kingdom gene transfer is initiated by the activity of Ti-plasmid encoded vir (virulence) genes in response to low-molecular-mass phenolic compounds such as acetosyringone. A. tumefaciens played a major role in plant genetic engineering and basic research in molecular biology, accounting for nearly $80 \%$ of the transgenic plants produced so far. Initially, it was believed that only dicotyledons, gymnosperms and a few monocotyledonous species could be transformed by this bacterium; but recent reports have totally changed this scenario by demonstrating that many 'recalcitrant' species not included in its natural host range can also be transformed, especially filamentous fungi.
\end{abstract}

Results: This paper describes an efficient and convenient Agrobacterium-mediated gene transformation system for successful delivery of T-DNA, carrying the genes coding for $\beta$-glucuronidase (uidA), green fluorescent protein ( $g f p$ ) and hygromycin phosphotransferase (hpt) to the nuclear genome of lignin degrading white-rot fungi such as Phanerochaete chrysosporium, Ganoderma sp. RCKK-02, Pycnoporous cinnabarinus, Crinipellis sp. RCK-1, Pleurotus sajorcaju and fungal isolate BHR-UDSC without supplementation of acetosyringone. The fungal transformants were confirmed by PCR and Southern hybridization. The expression vector PCAMBIA 1304-RCKK was constructed by the addition of GPD promoter from plasmid p416 to the binary vector backbone pCAMBIA1304, which controls uidA and gfp gene. Transmission Electron Microscope (TEM) analysis revealed the attachment of bacterial cells to the fungal hyphae. Transformation frequency varied from 50 to $75 \%$ depending on the fungal species used in this study. The transformation efficiency was maximum at $20^{\circ} \mathrm{C}$ whereas no transfer was observed at temperature above $29^{\circ} \mathrm{C}$.

Conclusion: These findings provide a rapid and reproducible transformation method without external addition of acetosyringone, which could be useful for improving white-rot fungi for their various biotechnological applications.

\section{Background}

White-rot fungi are primarily the major degraders of lignin. The general attack on lignocellulose by white-rot fungi encompasses a simultaneous decay of polysaccharides and lignin, but preferential degradation of lignin may also occur by selective lignin degraders $[1,2]$. The technology development based on biological delignification requires the use of a microorganism, which should

\footnotetext{
*Correspondence: kuhad85@gmail.com

Lignocellulose Biotechnology Laboratory, Department of Microbiology, University of Delhi South Campus, Benito Juarez Road, New Delhi-110021, India
}

degrade lignin selectively, rapidly, and exhaustively; process hard wood and soft wood equally and has high growth rate [3]. The microorganism may be expected to have the combination of these properties to determine its efficiency of processing lignocellulosic substrate. The majority of microorganisms lack combination of all properties. However, recombinant DNA technology has led to the emergence of the field of metabolic engineering, the purposeful and directed modification of intracellular metabolism; generate organisms with desirable growth characteristics and cellular properties. 
Agrobacterium tumefaciens is widely used to transform plant cells [4]. It has the natural ability to transfer a segment of DNA from its Ti plasmid, known as 'T-DNA' into plant or fungal cells so that the T-DNA integrates at random into the nuclear chromosomes [5-7]. As previously reported, Agrobacterium-mediated transformation (AMT) also leads to homologous recombination and facilitated gene knock-out. Moreover, AMT improves homologous recombination with appropriate vector constructions [8]. Recently, it has been shown that, under in-vitro conditions, the host range of Agrobacterium can be extended to non-plant eukaryotes [9-11]. An efficient protocol for AMT of Aspergillus awamori conidiospores has been reported by Michielse et. al. [12]. Using diverse Agrobacterium strains and isolates, vectors and number of inoculation and selection techniques, transgenics have been produced, which were previously thought to be 'recalcitrant' to Agrobacterium mediated gene transformation. The Agrobacterium mediated transformation of fungal as well as human cell line (HeLa, HEK293 and neuronal PC12 cells) have been reported [9].

Since last decade, there has been a surge of interest in functional genomics research in filamentous fungi, which has been facilitated by several important advances. In this context, fusing the promoter of gene of interest to a marker gene, such as the gene encoding green fluorescent protein (GFP) from Aequorea victoria, is an efficient way to study gene regulation in basidiomycetes (13). There are many possible combinations of transformation systems and functional genomics strategies available, however, all of them are not uniformly successful in filamentous fungi. The Agrobacterium-mediated genetic transformation has been proved to be a powerful tool in biotechnology and might become a system of choice for white-rot fungi as well [11]. However, absence of a reliable gene transfer system is the single largest obstacle precluding the use of molecular approaches for the genetic improvement of white-rot fungi [11].

The high transformation frequency, together with the precision and simplicity of T-DNA integration, makes T-DNA a suitable element for genome mutagenesis approaches in white-rot fungi such as gene tagging, promoter entrapment and gene activation, which can also be exploited in different biotechnological applications $[11,14]$. The genetic manipulation of a microorganism requires the development of plasmid-mediated transformation system that includes: (i) infusion of exogenous DNA into recipient cells; (ii) expression of genes present on the incoming DNA and (iii) stable maintenance and replication of the inserted DNA, leading to expression of the desired phenotypic trait [14]. Here, we demonstrate Agrobacterium-mediated transformation of
T-DNA carrying genes coding for uidA, gfp and $h p t$ in six white-rot fungi in the absence of acetosyringone.

\section{Methods \\ Organisms}

Phanerochaete chrysosporium, ATCC 32629 and Pycnoporous cinnabarinus, were kind gift from Late Prof. Karl-Erik L. Eriksson, University of Georgia, Athens, USA. Ganoderma sp. RCKK-02, Crinipellis sp. RCK-1, Pleurotus sajor-caju and fungal isolate BHR-UDSC were from our laboratory culture collection. The cultures were grown and maintained on malt extract agar (MEA) containing (g/l): malt extract 20.0, $\mathrm{KH}_{2} \mathrm{PO}_{4}$ 0.5, $\mathrm{MgSO}_{4} .7 \mathrm{H}_{2} \mathrm{O} 0.5, \mathrm{Ca}\left(\mathrm{NO}_{3}\right)_{2} .4 \mathrm{H}_{2} \mathrm{O} 0.5, \mathrm{pH} 5.4$ and at $30^{\circ} \mathrm{C} \pm 1^{\circ} \mathrm{C}[15]$.

\section{Antibiotic selection}

Fungal cultures were grown at different concentrations

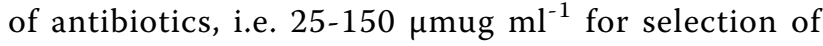
transformants.

\section{Plasmid construct and bacterial strains}

pCAMBIA1304, which contains a bacterial hpt gene driven by Cauliflower Mosaic Virus (CaMV) $35 \mathrm{~S}$ promoter and a gus:gfp fusion as a reporter gene under the influence of another CaMV $35 \mathrm{~S}$ promoter [16] was provided by Centre for Application of Molecular Biology for International Agriculture, Canberra, Australia. Escherichia coli strain DH5 $\alpha$ and A. tumefaciens strain GV3101 were obtained from Prof. Deepak Pental, Department of Genetics, University of Delhi South Campus, New Delhi, India. Vector with glyceraldehyde 3-phosphate dehydrogenase (GPD) fungal promoter, i.e. p416 [13,17] was procured from ATCC vector bank having accession number 87360 .

\section{Vector modification}

The vector pCAMBIA 1304-RCKK was constructed by modifying pCAMBIA 1304, the original binary vector. The $S a c I$ and $X b a I$ digested GPD promoter, obtained from vector $\mathrm{p}-416$ [17], was inserted to multiple cloning site (MCS) of pCAMBIA 1304. The hygromycin resistance gene was fused under CaMV $35 \mathrm{~S}$ promoter [16], whereas GFP - GUS fusion protein was expressed through GPD fungal promoter (Figure 1).

\section{Fungal transformation}

For transformation experiments, A. tumefaciens strain GV3101 was grown in $5 \mathrm{ml}$ of yeast extract broth (YEB) containing Kanamycin at concentration of $50 \mu \mathrm{g} / \mathrm{ml}$ for $48 \mathrm{~h}$ at $28^{\circ} \mathrm{C}, 250 \mathrm{rpm}$ [11]. One $\mathrm{ml}$ of fresh culture was transferred to $100 \mathrm{ml} \mathrm{YEB}$ and grown at $28^{\circ} \mathrm{C}, 250 \mathrm{rpm}$, up to an absorbance of 0.5 at $600 \mathrm{~nm}$. 


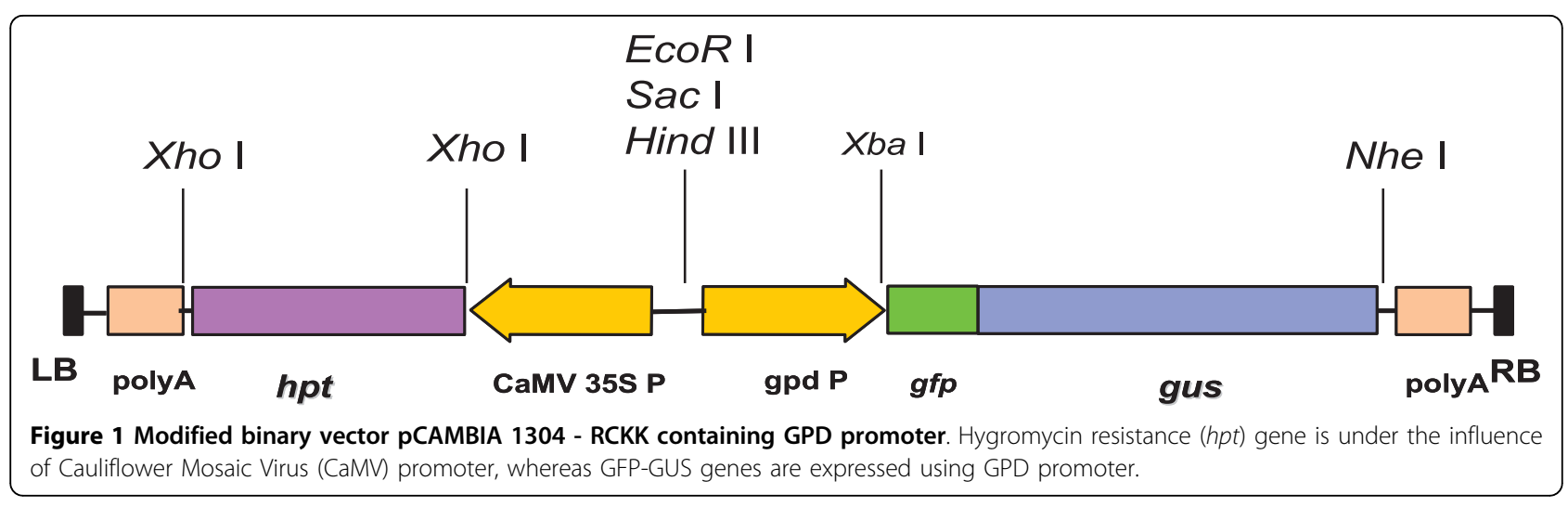

Two Petri dishes of different diameter were kept in a concentric position, placing smaller one in the centre of bigger Petri dish (Figure 2A). First, the inner Petri dish was poured with $2 \%$ MEA supplemented with $0.1 \%$ lignin and augmentin $(100 \mu \mathrm{g} / \mathrm{ml})$ and then bigger plate was poured with yeast extract agar (YEA) containing kanamycin at a concentration of $50 \mu \mathrm{g} / \mathrm{ml}$. Both the plates were poured very carefully so that media do not mix with each other. The MEA plate (inner one) was inoculated at the centre with a fungal disc, incubated at $28^{\circ} \mathrm{C}$ and it was allowed to grow till the hyphae cross the periphery of the inner plate and move on to the outer plate. Thereafter, Agrobacterium culture was plated carefully on the medium in outer plate, which already contains growing mycelia and co-cultivated at temperatures ranging from $20-29^{\circ} \mathrm{C}$ for $48 \mathrm{~h}$ (Table 1 and Figure 2A, B).

After co-cultivation, mycelial discs from peripheral region, where fungal hyphae reached to bacterial lawn, were cut randomly and washed with a concentration of $250 \mu \mathrm{g} / \mathrm{ml}$ augmentin (Medreich Sterilab Limited, India). Thereafter, the mycelial discs were transferred to MEA containing hygromycin at a concentration of $200 \mu \mathrm{g} / \mathrm{ml}$ and augmentin $(100 \mu \mathrm{g} / \mathrm{ml})$, and incubated at $28^{\circ} \mathrm{C}, 144 \mathrm{~h}$. The culture containing Petri plates were sealed with gas-porous tape (Micro-pore, India).

\section{Screening of transformants}

\section{Detection of reporter gene expression}

GUS histochemical assay was performed as described elsewhere [18]. After co-cultivation of fungal mycelia with Agrobacterium, four fungal discs ( $2 \mathrm{~mm}$ dia each) were randomly picked up and grown in malt extract $(2 \%, \mathrm{w} / \mathrm{v})$ at $100 \mathrm{rpm}, 30^{\circ} \mathrm{C}$ for 3 days in the presence of hygromycin at a concentration of $200 \mu \mathrm{g} / \mathrm{ml}$. Similarly, untransformed control fungal cultures were grown in the absence of hygromycin. This resulted in the development of small pellets and each pellet was considered as an individual transformant. The mycelial samples resistant to hygromycin were stained in X-gluc solution at $37^{\circ} \mathrm{C}$ overnight. Thereafter, the number of transformants in co-cultivated mycelia were compared with control fungal pellets after GUS staining. Transformation efficiency $(\eta)$ was calculated as:

$$
\eta=\frac{\text { no. of transformed pellet positive for GUS }}{\text { no. of wild type fungal pellets }} \times 100
$$

For the formation of the GFP chromophore, transgenic mycelia were incubated at $4^{\circ} \mathrm{C}$ for $2 \mathrm{~h}$ [19]. Fluorescent microscopy (Olympus Reflected Fluorescence System, bx 51; Olympus Optical Co., Ltd. Japan) of fungal hyphae was performed using Olympus camera DP70 for the imaging of GFP expression. GFP was detected with an excitation filter BP460-490 and barrier filter BA520IF. Images were captured using Olysia, software imaging application (Olympus Optical Co. Ltd., Japan) and processed electronically using Adobe Photoshop (Adobe Systems Inc., USA).

\section{Analysis of T-DNA integration and transgene expression}

Genomic DNA from the transformants was isolated as described earlier [20]. PCR analysis was performed with primer pairs 5'-CCGGATCCATGGTAGATCTGACTAG-3' and 5'-GCTTGCATGCTTAGTATAGTTCATCCATGC-3' for gfp-gus gene to amplify a $2.5 \mathrm{~kb}$ fragment. Genomic DNA digested with BamHI was analysed by Southern hybridization using radiolabelled $h p t$ gene probe [21]. All the transformed mycelia were also tested for the possibility of persistent Agrobacterium contamination. Fungal mycelia were grown on Luria Broth (LB) medium to screen out the bacterial contaminant. BamHI digested genomic DNA from the transformed lines was analysed by Southern blot hybridization using $\mathrm{Kan}^{R}$ probe.

\section{Confirmation of Agrobacterium-fungus attachment}

Fungal mycelia were harvested from the bacterial-fungal interface agar zone. Thereafter, fungal hyphae were fixed in $2.5 \%$ glutaraldehyde and $2 \%$ paraformaldehyde, prepared in $0.1 \mathrm{M}$ sodium phosphate buffer ( $\mathrm{pH} 7.4$ ) 


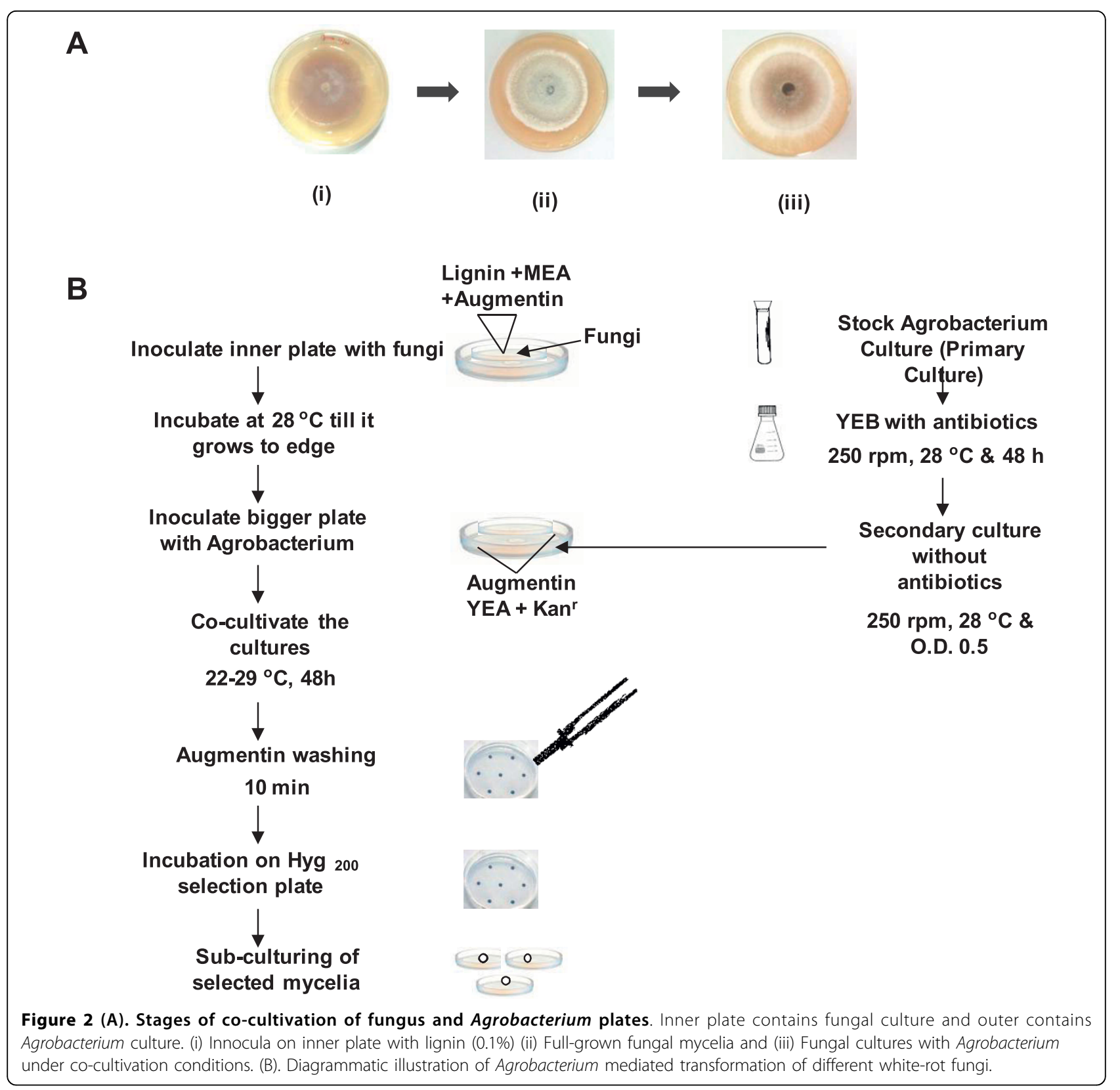

Table 1 Transformation efficiencies (\%) in different fungal species at varying co-cultivation temperatures

\begin{tabular}{lcccc}
\hline Basidomycetous Fungi & \multicolumn{3}{c}{ Percent transformation efficiency $(\boldsymbol{\eta}){ }^{*}$ at different Co-cultivation temperature } \\
\cline { 2 - 5 } & $\mathbf{2 0}^{\circ} \mathbf{C}$ & $\mathbf{2 3}^{\circ} \mathbf{C}$ & $\mathbf{2 6}^{\circ} \mathbf{C}$ & $\mathbf{2 9}^{\circ} \mathbf{C}$ \\
\hline Ganoderma sp. RCKK-02 & 65 & 48 & 32 & 17 \\
P. cinnabarinus & 65 & 45 & 30 & 15 \\
Crinipellis sp. RCK-1 & 75 & 65 & 48 & $\mathrm{ND}$ \\
Pleurotus sojur-caju & 50 & 34 & 45 & $\mathrm{ND}$ \\
P. chrysosporium & 75 & 63 & 34 & 20 \\
Fungal isolate BHR-UDSC & 50 & 30 & 18 & $\mathrm{ND}$ \\
\hline
\end{tabular}

ND- Not Detected

${ }^{*} \eta=\frac{\text { no. of transformed pellet positive for GUS }}{\text { no. of wild type fungal pellets }} \times 100$ 
and subjected to transmission electron microscopy (TEM) (Morgagni 268 D, Transmission Electron Microscopy, Fei, Holand) at Department of Anatomy, All India Institute of Medical Sciences (AIIMS), New Delhi.

\section{HPLC analysis of phenolics}

The fungi were grown on malt extract broth $(0.5 \%)$ supplemented with micronutrients (g/l), i.e. $\mathrm{KH}_{2} \mathrm{PO}_{4} 0.5$, $\mathrm{MgSO}_{4} .7 \mathrm{H}_{2} \mathrm{O} 0.5, \mathrm{Ca}\left(\mathrm{NO}_{3}\right)_{2} .4 \mathrm{H}_{2} \mathrm{O} 0.5$ and $1 \%$ lignin at pH 5.4 and temperature $30^{\circ} \mathrm{C}$ under static conditions. The samples were harvested on $10^{\text {th }}$ day and analysed for lignin degraded products. The cell-free culture filtrate was mixed with acetonitrile, vortexed and centrifuged for $10 \mathrm{~min}$ to pellet the remaining insoluble material. The supernatant was passed through $0.2 \mu$ mum membrane filter. Samples $(25 \mu \mathrm{l}$ each $)$ were applied to a Luna 5 u C18 HPLC column $(5 \mu$ mum particle size, $250 \times 4.6 \mathrm{~nm}$ ) under isocratic condition of $22 \%$ acetonitrile, $78 \%$ phosphoric acid from $1 \%$ stock. The authentic phenolics standards and lignin samples were analysed for lignin precursors and degraded intermediates by monitoring UV-absorbance at $280 \mathrm{~nm}$, maintaining constant flow rate of $0.5 \mathrm{ml} / \mathrm{min}$ (Waters, HPLC, Water Corporation, Milford, MA 01757, USA).

\section{Results and Discussion}

\section{Transformation and reporter gene expression}

Hygromycin at the concentration of $150 \mu$ mug ml ${ }^{-1}$ showed complete inhibition of different lignin degrading fungi, whereas it showed restricted growth at $125 \mu$ mug $\mathrm{ml}^{-1}$. Other antibiotics tested, i.e. ampicillin, kanamycin, rifampicin, gentamycin, did not show any significant growth inhibition even at $150 \mu \mathrm{mug} \mathrm{ml}{ }^{-1}$ concentration.

The fungal cultures when co-cultured with A. tumefaciens harboring hpt gene resulted in development of hygromycin-resistant $\left(\mathrm{Hyg}^{\mathrm{r}}\right)$ mycelia (Figure $\left.2 \mathrm{~B}\right)$. The DNA transfer events were studied by monitoring the transgene associated with T-DNA ( $g f p$, uidA and $h p t$ ) in $\mathrm{Hyg}^{\mathrm{r}}$ colonies. GUS histochemical assays after co-cultivation showed high frequency of transformation. A high percentage GUS positive cells were detected in the transformed mycelia (about $75 \%$ in Crinipellis sp. RCK$1 \& P$. chrysosporium), indicating that the cells received T-DNA (Table. 1). A standard transformation system of $P$. chrysosporium was used as a positive control which has been reported earlier [11]. Stable transformants showed the expression of GFP as detected by confocal microscopy (Figure 3). Interestingly $\mathrm{Hyg}^{\mathrm{r}}$ phenotype was retained even after sub-culturing the transformants in hygromycin- free medium for a period of 2 months.

The transformation results confirm the efficacy of both the promoter, i.e. CaMV $35 \mathrm{~S}$ and GPD, in the expression of $h p t$ and uidA gene, respectively. There are earlier reports of CaMV $35 \mathrm{~S}$ promoter in driving the expression of reporter genes in P. chrysosporium, Ganoderma lucidum, and Pleurotus citrinopileatus, the lignin degrading white-rot fungi $[11,16]$. Moreover, CaMV 35 $\mathrm{S}$ promoter used in the transformation studies provides an additional choice in basidiomycetes molecular studies, and allows the construction of shuttle vector system for alternative expression of genes in fungi and plants, which requires only minimal cloning manipulations [16].

The transfer efficiency was maximum at $20^{\circ} \mathrm{C}$ (Table 1) whereas no transfer was observed at temperature above $29^{\circ} \mathrm{C}$. Suppression in transformation at higher temperature could be attributed to loss of activity of A. tumefaciens to provide the virulence principle $[22,23]$. The conformational change in virA, resulting in inactivation of the protein at higher temperature has been reported [24]. Moreover, the sex pili involved in the transfer of T-DNA could be absent or unstable at higher temperature [25]. Our results suggest that co-cultivation at low temperature could significantly increase the transformation frequency.

In the present study, the white-rot fungi when grown in malt extract media supplemented with lignin, were observed to produce lignin degraded products compared to control medium (without lignin). White-rot fungi have been shown to partially mineralize lignin in axenic culture [26]. A large number of phenolic secondary metabolites are also reported in the lignin degradation pathway $[26,27]$. These phenolic compounds, which are normally involved in lignin biosynthesis, serve as inducers (or co-inducers) of bacterial virulence genes [28]. The vir-inducing activities of the lignin precursors have been discussed in terms of the biology of Agrobacterium $[29,30]$.

\section{HPLC analysis of the phenolics}

The HPLC profile of the degraded lignin compound confirmed the presence of different intermediates of lignin synthesis pathway. The presence of acetosyringone in fungus-degraded lignin supernatant advocates the transformation of fungal mycelia grown in lignin-supplemented media. In addition to well established vir-gene inducer, i.e. acetosyringone, we also detected some additional phenolic compounds like caffeic acid, 4-hydroxybenzyl alcohol and cinnamic acid (Figure 4). HPLC profile also showed few unidentified peaks, which made us to hypothesize that there might be some synergistic or cumulative effect of different phenolic compounds, resulting in high transformation efficiency.

\section{Molecular analysis of nuclear integration}

The Hyg ${ }^{\mathrm{r}}$ transformants were PCR screened with gus-gfp primers which resulted in an expected amplified product of $2.5 \mathrm{~kb}$ (Figure 5a). Randomly selected transformants 


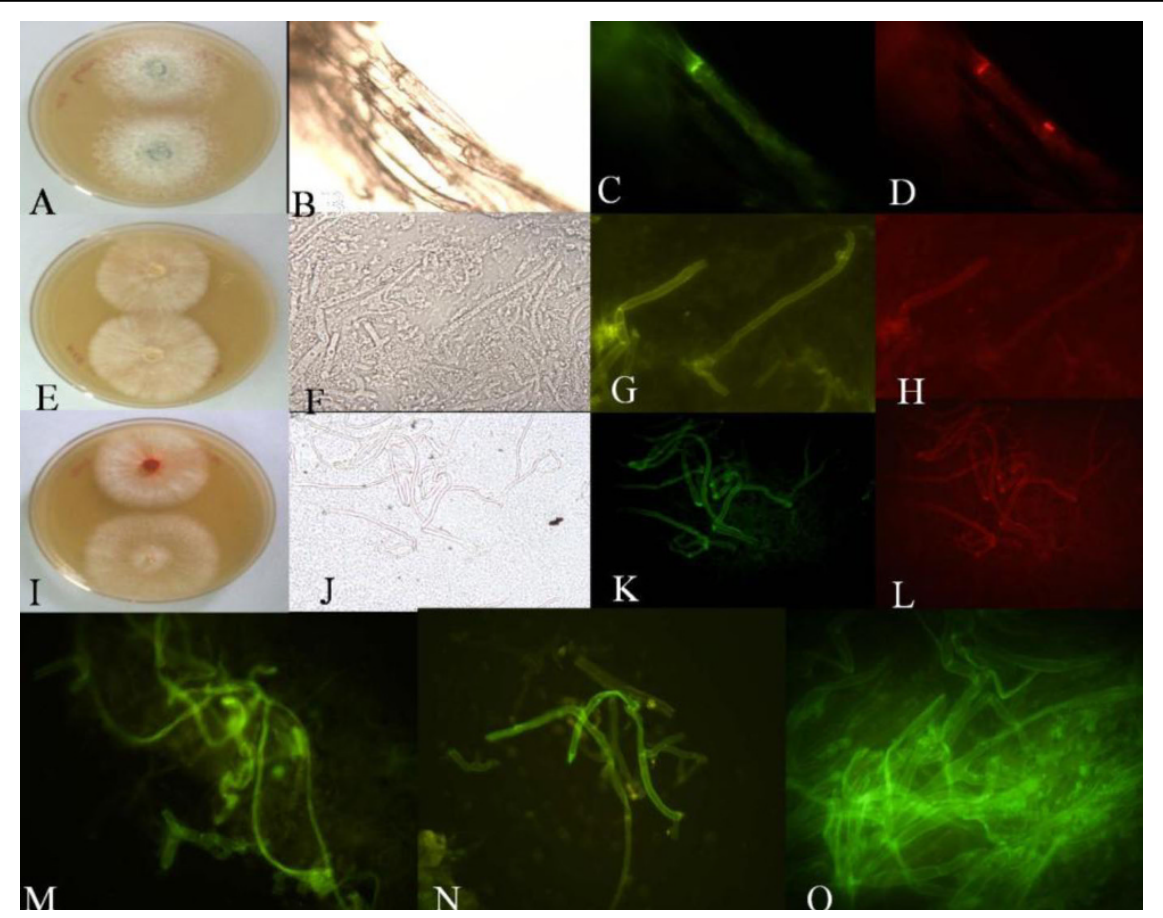

Figure 3 Agrobacterium mediated in-vitro gene transfer as measured through UV-florescence using different excitation filters (BP460490) and their hygromycin selection. (A). Ganoderma sp. RCKK-02; (E). Crinipellis sp. RCK-1; (I). P. cinnabarinus (M). P. sojur-caju; (N). P. chrysosporium; (O). Fungal isolate BHR-UDSC. (B,F,J) Images under Bright field; (C, D, G, H, K, L) GFP-tagged mycelia using different excitation filters (BP460-490) and barrier filter BA520IF.

were further used for molecular analysis. The BamHI digested genomic DNA from transformants was hybridized to $\mathrm{P}^{32} \alpha$ dATP labelled $h t p$. The Southern analysis confirmed transformation and also revealed that the number of inserts in different transformed lines varied from one to four (Figure $5 \mathrm{~b}$ ). All the $\mathrm{Hyg}^{\mathrm{r}}$ mycelia were tested for the possibility of Agrobacterium contamination. Fungal mycelia were grown on LB medium to screen any bacterial contamination. The BamHI digested genomic DNA samples from the transformed lines were analysed by Southern hybridization using $\mathrm{Kan}^{R}$ probe. No hybridization was detected in the transformants, which ruled out the possibility of any bacterial contamination (Figure 5c).

\section{Agrobacterium-fungal attachment confirmation}

Attachment of Agrobacterium to fungal mycelia was confirmed by TEM analysis. The TEM results revealed bacterial attachment to fungal cells. This method of coculturing might have resulted in a substantial increase in concentration of bacteria which eventually facilitated transfer of T-DNA to fungal cells without wound formation $[31,32]$.

The competence of plant cells for Agrobacterium mediated DNA transfer is not necessarily linked to cell damage. T-DNA integration, therefore, does not absolutely need the wounding activities in the plant cell.
This indicates that the well-known requisite of a wound for transformation is probably a special sensory attraction that Agrobacterium developed to recognize a natural niche [33]. The transfer of T-DNA from A. tumefaciens to plant genome, by a type IV secretion system (T4SS), most probably resembles DNA transfer between bacteria during conjugation. Indeed, this transfer mechanism was found to be functional during conjugative transfer of Ti plasmids between Agrobacterium and other bacteria as well as plant cells, which in turn suggested that Agrobacterium can transfer genetic material with other non-plant species [10]. The Agrobacterium radiobacter has been reported to be associated with 10 different strains of $P$. chrysosporium [34]. Thus, it is likely that bacteria and fungi act together either simultaneously or consecutively to degrade lignin or its breakdown products. As Agrobacterium and white-rot fungi share a common habitat, they encounter each other very often. Our transformation experiment suggests that TDNA transfer from Agrobacterium to white-rot fungi does indeed occur in nature, and horizontal DNA transfer between kingdoms may be more frequent and extensive, which also support our previous observations [11]. Moreover, basidiomycetes are more closely related to higher eukaryotes, therefore, it is a better choice as a heterologous system for the expression of higher eukaryotic genes. 


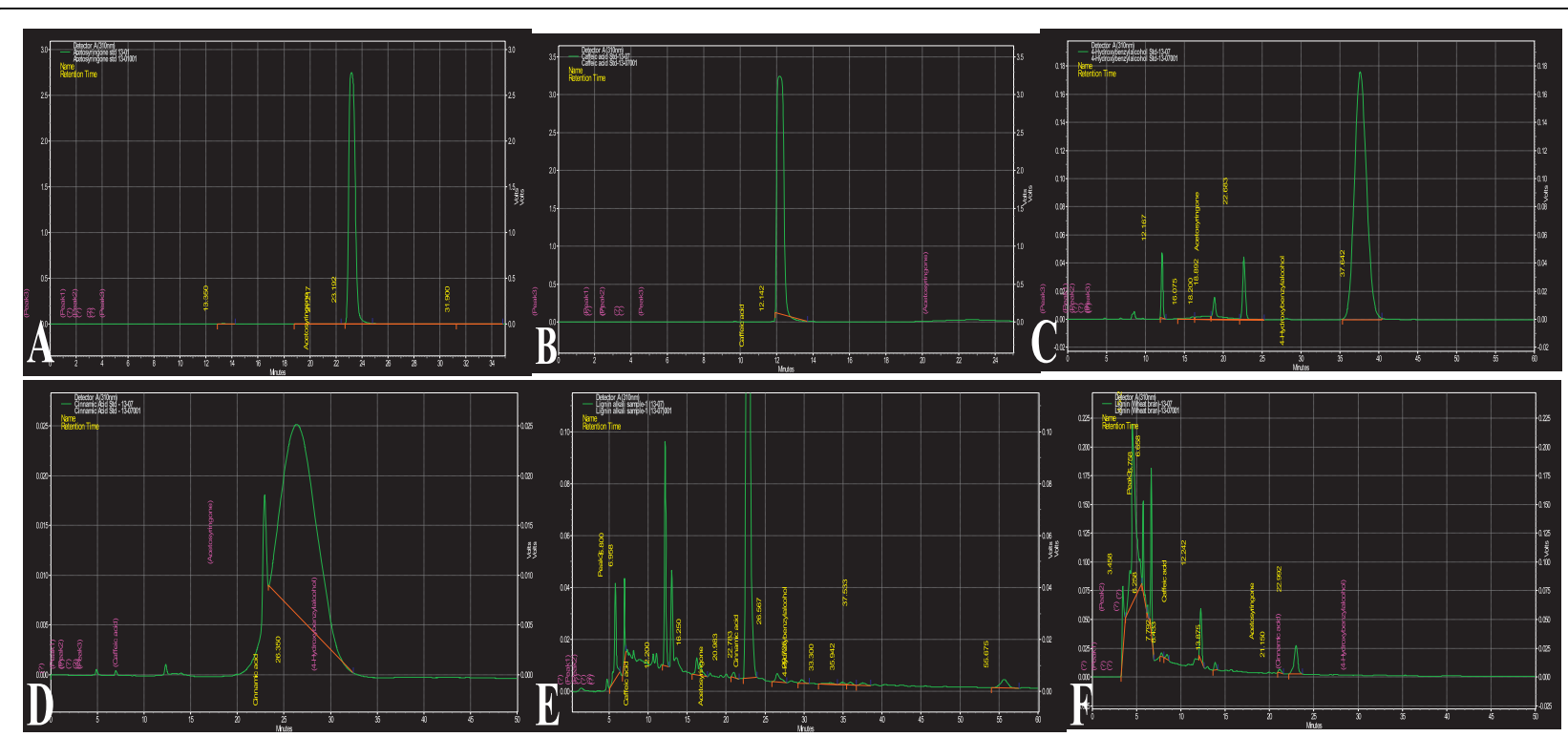

Figure 4 HPLC profiles of phenolic extracts from lignin (commercial) (E) and wheat bran (F). The peak at retention time (RT) 23.19 was identified as acetosyringone. Different compounds of lignin monomer pathways were used as standards, i.e. acetosyringone, RT 23.19 (A); caffeic acid, RT12.142 (B); 4-hydroxybenzylalcohol RT 37.642 (C) and cinnamic acid RT 26.350 (D).

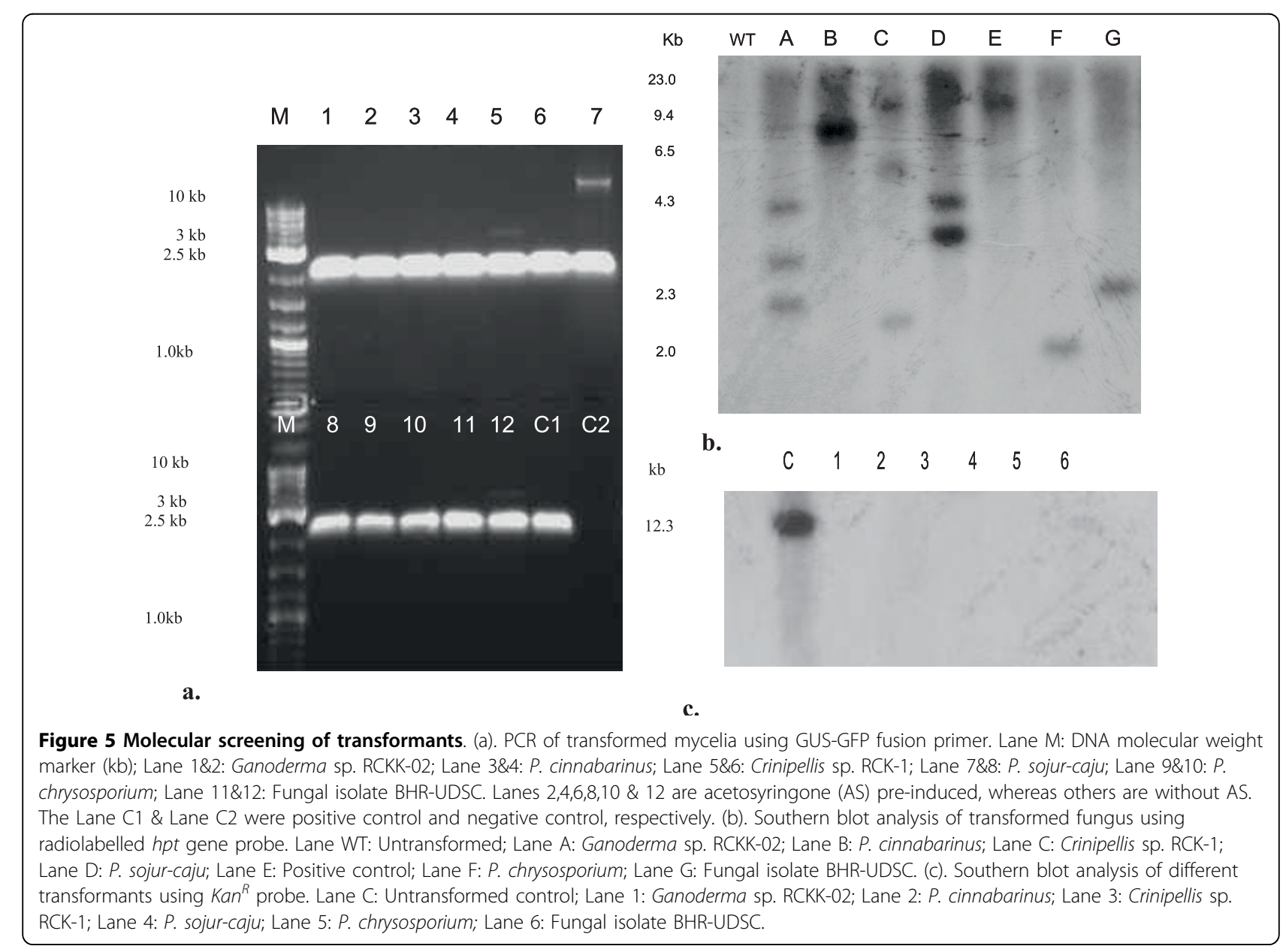




\section{Conclusion}

The transformation results suggest that co-cultivation at low temperature could significantly increase the transformation frequency. The strategy to use both CaMV 35 $\mathrm{S}$ and GPD promoter demonstrated comparable efficacy in the expression of $h p t$ and uidA genes in white-rot fungi, respectively. Moreover, these findings provide a rapid and reproducible transformation method without external addition of acetosyringone, which could be useful for improving white-rot fungi for their various biotechnological applications.

\author{
Abbreviations \\ CaMV: cauliflower mosaic virus; MCS: multiple cloning site; GDP: \\ glyceraldehyde 3-phosphate dehydrogenase; MEA: malt extract agar; YEA: \\ yeast extract agar; TEM: transmission electron microscope.
}

\section{Acknowledgements}

We thank Prof. Deepak Pental, Vice-Chancellor, University of Delhi, for experimental facilities and Agrobacterium cultures. The authors are grateful to Prof. J. P. Khurana, Department of Plant Microbiology \& Biotechnology and Dr. P. Burma, Department of Genetics, University of Delhi South Campus, New Delhi, for their help in improving the manuscript. The authors also acknowledge the grant-in-aid from Department of Biotechnology, Government of India, for the project entitled "Bioconversion of Plant Biomass into Biotech Feed".

\section{Authors' contributions}

KKS conducted the experiments, analyzed the data and wrote the manuscript. RCK (corresponding author) planned the work, coordinated the study and critically finalised the manuscript. Both agree to submit the manuscript to BMC Biotechnology.

Received: 19 March 2010 Accepted: 14 September 2010 Published: 14 September 2010

\section{References}

1. Eriksson K-EL, Blanchette RA, Ander P: Biodegradation of lignin, in Microbial and enzymatic degradation of wood and wood components. Springer-Verlag, Berlin 1990, 225-333.

2. Kuhad RC, Singh A, Eriksson K-EL: Microorganisms and enzymes involved in the degradation of plant fiber cell walls. Adv Biochem Eng Biotechnol 1997, 57:45-125.

3. Aleksandrova GP, Petrov AN, Medvedeva SA, Babkin VA: Screening of Lignin-degrading Fungi for Biotechnological Purposes. Appl Biochem Microbiol 1998, 34:245-250.

4. Gelvin SB: Agrobacterium VirE2 Proteins can Form a Complex with T Strands in the Plant Cytoplasm. J Bacteriol 1998, 180:4300-4302.

5. Hooykaas PJJ, Beijersbergen AGM: The virulence system of Agrobacterium tumefaciens. Annu Rev Plant Pathol 1994, 32:1578-1579.

6. Bundock P, Den Dulk-Ras A, Beijersbergen A, Hooykas PJJ: Transkingdom TDNA transfer from Agrobacterium tumefaciens to Saccharomyces cerevisiae. EMBO J 1995, 14:3206-3214.

7. De Groot MJA, Hooykaas PJJ, Beijersbergen AGM: Agrobacterium tumefaciens-mediated transformation of filamentous fungi. Nat Biotechnol 1998, 16:839-842.

8. Bardiya N, Shiu PKT: Cyclosporin A-resistance based gene placement system for Neurospora crassa. Fungal genet Biol 2007, 44:307-314.

9. Kunik T, et al: Genetic transformation of HeLa cells by Agrobacterium. Proc Natl Acad Sci USA 2001, 98:1871-1876.

10. Lacroix B, Tzfira T, Vainstein A, Citovsky V: A case of promiscuity: Agrobacterium's endless hunt for new partners. Trends Genet 2006, 22(1):29-37.

11. Sharma KK, Gupta S, Kuhad RC: Agrobacterium-mediated delivery of marker genes to Phanerochaete chrysosporium mycelial pellets: a model transformation system for white-rot fungi. Biotechnol Appl Biochem 2006, 43:181-186.

12. Michielse CB, Hooykaas PJJ, van den Hondel CAMJJ, Ram AFJ: Agrobacterium-mediated transformation of the filamentous fungus Aspergillus awamori. Nat Protocols 2008, 3:1671-1678.

13. Ma B, Mayfield MB, Gold MH: The green fluorescent protein gene functions as a reporter of gene expression in Phanerochaete chrysosporium. Appl Environ Microbiol 2001, 67:948-955.

14. Ruiz-Díez B: Strategies for the transformation of filamentous fungi. J Appl Microbiol 2002, 92(2):189-195.

15. Vasdev K, Kuhad RC: Induction of laccase production in Cyathus bulleri under shaking and static condition. Foila Microbiol 1994, 39:326-330.

16. Sun $L, C a i H, X u W, H u Y, L i n Z$ : CaMV35 S promoter direct $\beta$ glucuronidase expression in Ganoderma lucidum and Pleurotus citrinopileatus. Mol Biotechnol 2002, 20(3):239-244.

17. Donggiun K, Gustin JL, Lahner B, Persans MW, Baek D, Yun DJ, Salt DE: The plant CDF family member TgMTP1 from the Ni/Zn hyperaccumulator Thlaspi goesingense acts to enhance efflux of $\mathrm{Zn}$ at the plasma membrane when expressed in Saccharomyces cerevisiae. Plant J 2004, 39:237-251.

18. Jefferson RA: Assaying chimeric genes in plants: the GUS gene fusion system. Plant Mol Biol Rep 1987, 5:387-405.

19. Cody CW, Prasher DC, Westler WM, Prendergast FG, Ward WW: Chemical structure of the hexapeptide chromophore of the Aequorea greenfluorescent protein. Biochem 1993, 32(5):1212-1218.

20. Kuhad RC, Kapoor RK, Lal R: Improving the yield and quantity of DNA isolated from white-rot fungi. Folia Microbiol 2004, 49(2):112-116.

21. Sambrook J, Fritsch EF, Maniatis T: A Laboratory Manual. Cold Spring Harbor Laboratory Press, New York 1989.

22. Braun AC: Thermal studies on the factors responsible for tumor initiation in crown gall. Am J Bot 1947, 34:234-240.

23. Braun AC: A physiological basis for autonomous growth of the crowngall tumor cell. Proc Natl Acad Sci USA 1958, 44:344-349.

24. Jin S, Song Y-N, Deng W-Y, Gordon M, Nester EW: The regulatory VirA protein of Agrobacterium tumefaciens does not function at elevated temperatures. J Bacteriol 1993, 175:6830-6835.

25. Fullner KJ, Nester EW: Temperature affects the T-DNA transfer machinery of Agrobacterium tumefaciens. J Bacteriol 1996, 178(6):1498-1504.

26. Trojanowski J, Haider $\mathrm{K}$, Hutterman A: Decomposition of ${ }^{14} \mathrm{C}$-labelled lignin holocellulose and lignocellulose by mycorrhizal fungi. Arch Microbiol 1984, 139:202-206.

27. Burtscher $\mathrm{E}$ : Chromatographic analysis of biomass reaction products produced by hydrothermolysis of poplar wood. J Chromatogr 1987, 390:401-412.

28. Gavnholt B, Larsen K: Molecular biology of plant laccase in relation to lignin formation. Physiol Plant 2002, 116:273-280.

29. Gelvin SB: Agrobacterium and plant genes involved in T-DNA transfer and integration. Annu Rev Plant Physiol Plant Mol Biol 2000, 51:223-256.

30. Spencer PA, Towers PAS: Specificity of signal compounds detected by Agrobacterium tumefaciens. Phytochem 1998, 27(9):2781-2785.

31. Matthysse AG, Holmes KV, Gurlitz RHG: Elaboration of cellulose fibrils by Agrobacterium tumefaciens during attachment to carrot cells. J Bacteriol 1981, 145(1):583-595.

32. Duarte RTD, Staats CC, Fungaro MHP, Schrank A, Vainsten MH, FurlanetoMaia L, Nakamura CV, de Souza W, Furlaneto MC: Development of a simple and rapid Agrobacterium tumefaciens-mediated transformation system for the entomopathogenic fungus Metarhizium anisopliae var. acridum. Lett Appl Microbiol 2007, 44:248-254.

33. Escudero J, Hohn B: Transfer and integration of T-DNA without cell injury in the host plant. Plant Cell 1997, 9:2135-2142

34. Seigle-Murandi F, Guiraud P, Croize J, Falsen E, Eriksson KL: Bacteria Are Omnipresent on Phanerochaete chrysosporium Burdsall. Appl Environ Microbiol 1996, 62(7):2477-2481.

doi:10.1186/1472-6750-10-67

Cite this article as: Sharma and Kuhad: Genetic transformation of lignin degrading fungi facilitated by Agrobacterium tumefaciens. BMC Biotechnology 2010 10:67. 